\title{
Suicídios em uma organização policial-militar do sul do Brasil
}

\section{Suicides in a military police organization in southern Brazil}

\author{
Gustavo Klauberg Pereira'1 (D), Amanda Batista Madruga², Edelu Kawahala² \\ 'Diretoria de Saúde da Polícia Militar de Santa Catarina (DSPS) - Florianópolis (SC), Brasil. \\ ${ }^{2}$ Centro Universitário Estácio de Sá, São José (SC), Brasil.
}

Como citar: Pereira GK, Madruga AB, Kawahala E. Suicídios em uma organização policial-militar do sul do Brasil. Cad Saúde Colet, 2020;28(4):500-509. https://doi.org/10.1590/1414-462X202028040562

\section{Resumo}

Introdução: O suicídio é considerado um problema de saúde pública. Todos os anos 840 mil pessoas tiram a própria vida. Em policiais militares as taxas de suicídio também são altas. Objetivo: Este trabalho buscou investigar características socio-ocupacionais em casos de suicídios de policiais militares de Santa Catarina, Brasil, ocorridos entre os anos de 2012 a 2016. Método: Trata-se de um estudo documental, descritivo e de abordagem quantitativa, que utilizou informações socio-ocupacionais disponibilizadas pela organização sobre casos de suicídios de policiais militares. Resultados: Todos os policiais militares que cometeram suicídio eram do sexo masculino $(n=14)$ e boa parte tinha filhos $(85,71 \%)$. Dos casos de suicídio, $85,71 \%$ ocorreram na carreira de praças, especialmente no primeiro grau na hierarquia militar (soldados), com metade dos casos $(n=7)$. Em todos os casos, havia parte do salário comprometido com empréstimos ou dívidas financeiras. Conclusão: Características ocupacionais importantes em determinadas situações podem vir a se tornar um fator de risco ao suicídio de policiais militares. Outras pesquisas são necessárias, especialmente considerando outras fontes de informação importantes não utilizadas nesta investigação. Palavras-chave: suicídio; polícia militar; saúde mental; policial.

\begin{abstract}
Background: Suicide is considered a public health problem. Every year 840,000 people take their own lives. In military police, suicide rates are also high. Objective:This study aimed to investigate occupational and social characteristics in cases of suicide of military police officers from Santa Catarina, Brazil, from 2012 to 2016. Method: This is a documentary, descriptive and quantitative study, using socio-occupational information provided by the organization about suicide cases of military police officers. Results: All military police officers who committed suicide are male $(n=14)$ and most have children $(85.71 \%)$. About $85.71 \%$ of the suicide cases occurred in lower rank positions, especially in the first degree in the military hierarchy. Soldiers accounted for half of the cases $(n=7)$. In all cases, part of the salary was committed with loans or financial debts. Conclusion: Important occupational characteristics in certain situations may become a risk factor for suicide of military police officers. Further research is needed, especially considering other important sources of information not used in this investigation.
\end{abstract}

Keywords: suicide; military police; mental health; police officer.

\section{INTRODUÇÃO}

Foi a partir da década de 1950, por meio de uma subespecialidade da psiquiatria denominada suicidologia, que o fenômeno do suicídio passou a ser considerado um problema de saúde pública. Os pesquisadores da comunidade científica, então, investiram esforços

Trabalho realizado utilizou dados secundários disponibilizados pela Polícia Militar de Santa Catarina (PMSC) -

Florianópolis (SC), Brasil.

Correspondência: Gustavo Klauberg Pereira. E-mail: gkpgustavo@gmail.com

Fonte de financiamento: nenhuma.

Conflito de interesses: nada a declarar.

Recebido em: Nov. 26, 2018. Aprovado em: Nov. 04, 2019
Este é um artigo publicado em acesso aberto (Open Access) sob a licença Creative Commons Attribution, que permite uso, distribuição e reprodução em qualquer meio, sem restrições desde que o trabalho original seja corretamente citado. 
para produzir conhecimento sobre esse fenômeno, incluindo explicações bioquímicas, farmacológicas, psiquiátricas, sociológicas e psicológicas'.

O suicídio é a morte resultante, direta ou indiretamente, de atos praticados pela própria vítima conscientes da produção de tal resultado 2 .É considerado uma ação pessoal e intencional, com plena expectativa de um resultado fatal ${ }^{3}$.

A cada ano, aproximadamente 840 mil pessoas cometem suicídio no mundo, o que representa um autoextermínio a cada 40 segundos e uma taxa de 11,6 suicídios por 100 mil indivíduos/ano. No Plano de Ação de Saúde Mental 2013-2020, os Estados-membros da OMS comprometeram-se a reduzir a taxa de suicídio para $10 \%$ até 2020 , implicando a esse fenômeno um grau de alta prioridade na agenda de saúde pública mundial ${ }^{4}$.

O Brasil ocupa a oitava posição no ranking de países da América em número de suicídios ${ }^{5}$, com uma taxa de 4,5 casos de autoextermínio a cada 100 mil habitantes ${ }^{6}$. Já Santa Catarina é um dos estados do país com os maiores coeficientes nacionais: 7 casos a cada 100 mil habitantes.

O suicídio está entre as principais causas de morte de policiais no mundo, e os estudos sobre esse fenômeno ocorrem, em sua grande maioria, em países desenvolvidos, existindo poucos dados sobre o Brasil'7. A revisão de literatura das evidências disponíveis na literatura internacional identificou que a interação de cinco fatores principais associados ao policiamento aumentam o risco do suicídio em policiais: estresse organizacional, traumas de incidentes críticos, trabalho por turnos, problemas de relacionamento e uso e abuso de álcool ${ }^{8}$.

O maior estudo militar longitudinal dos Estados Unidos $(n=151.597)$ avaliou o impacto na saúde de quem serviu às forças armadas. Foram encontrados 83 casos de suicídios $(11,73 / 100$ mil militares ao ano $-95 \% \mathrm{Cl}, 9,21-14,26)$, e o risco de suicídio foi associado à depressão, transtorno maníaco-depressivo e problemas com álcool, porém não houve associação de risco de suicídio às vivências de combate?

A autópsia psicológica realizada em 39 policiais da força francesa que cometerem suicídio, identificaram eventos pessoais implicados na suicidalidade, cujas principais razões encontradas para o suicídio foram os problemas conjugais, além de todos sofrerem de transtornos mentais e comportamentais, especialmente depressão ${ }^{10}$. Sintomas de estresse pós-traumático aumentaram significativamente as associações entre falta de apoio organizacional e desesperança, importante fator de risco de suicídio em policiais ${ }^{11}$.

No Brasil, um trabalho consistente com policiais do Rio de Janeiro encontrou associação do suicídio com insatisfação com a corporação, transferências de local de trabalho sem consentimento ou aviso prévio, baixo nível de sociabilidade e de confiança interpessoal, além de problemas de sono e de depressão ${ }^{12}$. Identificou, ainda, uma taxa de suicídio 7,2 vezes maior do que os casos de autoextermínio encontrados na população em geral ${ }^{12}$.

Na Polícia Militar de São Paulo, a taxa de suicídio entre os policiais é 5,7 vezes maior que a população do estado de São Paulo e 6,5 vezes maior que a média da população brasileira ${ }^{6}$. Um estudo ${ }^{7}$ avaliou a incidência e o perfil sociodemográfico de suicídios de policiais militares do Rio Grande do Sul ocorridos entre 2006 e 2016. A análise das 31.110 causas-morte indicou que morreram mais policiais militares por suicídio $(n=43)$ que por mortes relacionadas ao trabalho $(n=16)$.

Outros estudos apontam para a vulnerabilidade dessa classe profissional por causa do alto risco de adoecimento mental, pois, além de lidarem frequentemente com riscos reais de morte, estado de alerta e fadiga, com frequência apresentam distúrbios de sono, depressão e alto consumo de substâncias psicoativas, situações ligadas ao suicídio ${ }^{13-16}$.

De modo geral, não é um fator isolado que predispõe um policial à ideação suicida, mas sim o efeito concentrado de múltiplos fatores de risco que aumentam as chances do autoextermínio ${ }^{8}$. As altas taxas de suicídio de uma relevante categoria profissional para a sociedade e as recomendações de importantes instituições mundiais de saúde acerca da priorização de políticas públicas para a prevenção do suicídio levaram a presente investigação a caracterizar o perfil socio-ocupacional do policial militar que comete suicídio em Santa Catarina. 


\section{MÉTODO}

Esta investigação foi autorizada pela Polícia Militar de Santa Catarina (PMSC). Trata-se de um estudo transversal, descritivo, retrospectivo e quantitativo, que utilizou dados secundários sobre o suicídio de 14 policiais militares de Santa Catarina, ocorridos entre 2012 e 2016.

Todos os dados disponibilizados pela Diretoria de Saúde e Promoção Social sobre os casos de autoextermínio foram analisados. Foram utilizados como fontes de informação documentos e dados do sistema de recursos humanos da organização. A análise de documentos permite identificar, avaliar e aferir informações disponíveis com um propósito específico e apresenta vantagens de baixo custo e de credibilidade de informações ${ }^{17,18}$.

Foram acessadas as informações do Sistema Integrado de Gestão de Recursos Humanos (SIGRH) do estado de Santa Catarina para a obtenção de detalhes socio-ocupacionais, como raça, escolaridade, tempo de serviço na Polícia Militar, estado civil, quantidade de filhos, histórico de afastamento para tratamento de saúde, histórico de punições por transgressões disciplinares ou de comportamento profissional, além de documentos de setores de psicologia e de medicina da Diretoria de Saúde e Promoção Social da PMSC. Os dados acessados por meio do SIGRH tiverem um critério temporal retrospectivo de cinco anos, contados a partir da data do óbito do policial militar, por exemplo, se houve afastamento para tratamento de saúde nos últimos cinco anos anteriores à data do suicídio.

As informações quantitativas, como quantidade de dias afastados do trabalho, idade e tempo de serviço, foram organizadas e analisadas descritivamente com média e frequência por meio do software de programa estatístico IBM SPSS 20.0. Já as informações qualitativas foram categorizadas por similaridade de conteúdo, algumas previamente, como as transgressões disciplinares, que são descritas no regulamento disciplinar da PMSC, e outras a posteriori, como as situações de processo de separação conjugal ou de exclusão da organização vivenciadas pelos policiais militares antes do autoextermínio .

\section{RESULTADOS}

As informações levantadas possibilitaram identificar um perfil socio-ocupacional de maior risco entre os policiais militares que praticaram autoextermínio. Os policiais militares suicidas predominaram na faixa etária de 40 a 47 anos. A maioria era do sexo masculino, casada, com filhos e escolaridade até ensino médio, além de predominar o autoextermínio entre os policiais da carreira de praças e mais próximos da aposentadoria.

No período de 2012-2016, ocorreram 14 suicídios de policiais militares em Santa Catarina, em um contingente de aproximadamente 10.500 policiais. No período analisado, o ano de 2015 apresentou a maior ocorrência de suicídios (71,42\%). A naturalidade (local de nascimento) do policial se distribui em estados do Sul e do Sudeste, com 11 policiais naturais de Santa Catarina e 3 de outros estados (Tabela 1).

Todos os 14 policiais militares que cometeram suicídio eram do sexo masculino, dos quais $12(85,71 \%)$ tinham filhos e se autodeclaravam brancos. Metade $(n=7)$ tinha entre 40 e 47 anos de idade, e 4 (28,57\%) tinham 51 anos de idade ou mais (Tabela 1$)$.

Quanto ao estado civil da amostra, 9 (64,29\%) eram casados, 3 (21,43\%), solteiros, e 2 (14,29\%), separados. O ensino médio foi o grau de escolaridade predominante (64,29\%), embora $3(21,43 \%)$ policiais possuíssem especialização e $2(14,29 \%)$ tivessem ensino superior (Tabela 1).

Dos policiais militares, $3(21,43 \%)$ cometeram suicídio na primeira década da carreira, 2 (14,29\%) cometeram na segunda década da carreira (período compreendido entre 11 e 20 anos de serviço), 6 (42,86\%) encontravam-se na última década da carreira na instituição e $3(21,43 \%)$ estavam aposentados. A maioria $(85,71 \%)$ era da carreira de praças, especialmente soldados $(n=7)$, e somente $2(14,28 \%)$ eram da carreira de oficialato (Tabela 1$)$.

Todos apresentaram algum percentual da renda salarial direcionada para o pagamento de empréstimos ou dívidas financeiras (Figura 1). Em média, a população examinada apresentou $1 / 4$ do seu salário destinado ao pagamento de empréstimos ou dívidas financeiras. Tal situação ocorreu mais com policiais militares da carreira de praças, que apresentaram, em média, 
Tabela 1. Perfil socio-ocupacional de policiais militares suicidas em Santa Catarina no período de 2012 a 2016 $(n=14)$

\begin{tabular}{|c|c|c|}
\hline Variável & $\mathbf{N}$ & $\%$ \\
\hline \multicolumn{3}{|l|}{ Naturalidade } \\
\hline SP & 1 & 7,14 \\
\hline PR & 1 & 7,14 \\
\hline SC & 11 & 78,57 \\
\hline RS & 1 & 7,14 \\
\hline \multicolumn{3}{|l|}{ Regime de trabalho } \\
\hline Inativo (aposentado) & 2 & 14,29 \\
\hline Ativo & 12 & 85,71 \\
\hline \multicolumn{3}{|l|}{ Carreira } \\
\hline Praças & 12 & 85,71 \\
\hline Oficiais & 2 & 14,29 \\
\hline \multicolumn{3}{|l|}{ Estado civil } \\
\hline Solteiro & 3 & 21,43 \\
\hline Casado & 9 & 64,29 \\
\hline Separado & 2 & 14,29 \\
\hline \multicolumn{3}{|l|}{ Faixa etária } \\
\hline 26 a 32 anos & 3 & 21,43 \\
\hline 40 a 47 anos & 7 & 50,00 \\
\hline 51 ou mais & 4 & 28,57 \\
\hline \multicolumn{3}{|l|}{ Tempo de serviço } \\
\hline 1 a 10 anos & 4 & 28,57 \\
\hline 11 a 20 anos & 2 & 14,29 \\
\hline 21 a 30 anos & 8 & 57,14 \\
\hline \multicolumn{3}{|l|}{ Escolaridade } \\
\hline Ensino médio & 9 & 64,29 \\
\hline Ensino superior & 2 & 14,29 \\
\hline Especialização & 3 & 21,43 \\
\hline
\end{tabular}

SP: São Paulo; PR: Paraná; SC: Santa Catarina; RS: Rio Grande do Sul.

de $22,5 \%$ do salário comprometimento com empréstimos ou dívidas, com percentuais entre $0,72 \%$ e $39,84 \%$. Os oficiais, por sua vez, apresentaram, em média, $9,42 \%$ da renda salarial destinada ao pagamento de empréstimos ou outras dívidas.

De modo geral, os militares possuem prescrição legal e disciplinar sobre suas condutas, as quais são passíveis de punição administrativa. Existem mais de 100 transgressões no regulamento disciplinar militar, que, apuradas e julgadas, podem gerar advertência, repreensão, detenção e prisão. Na amostra, 10 policiais militares $(71,42 \%)$ não tinham nenhum tipo de punição registrada em suas fichas de conduta nos cinco anos anteriores ao suicídio. Daqueles 


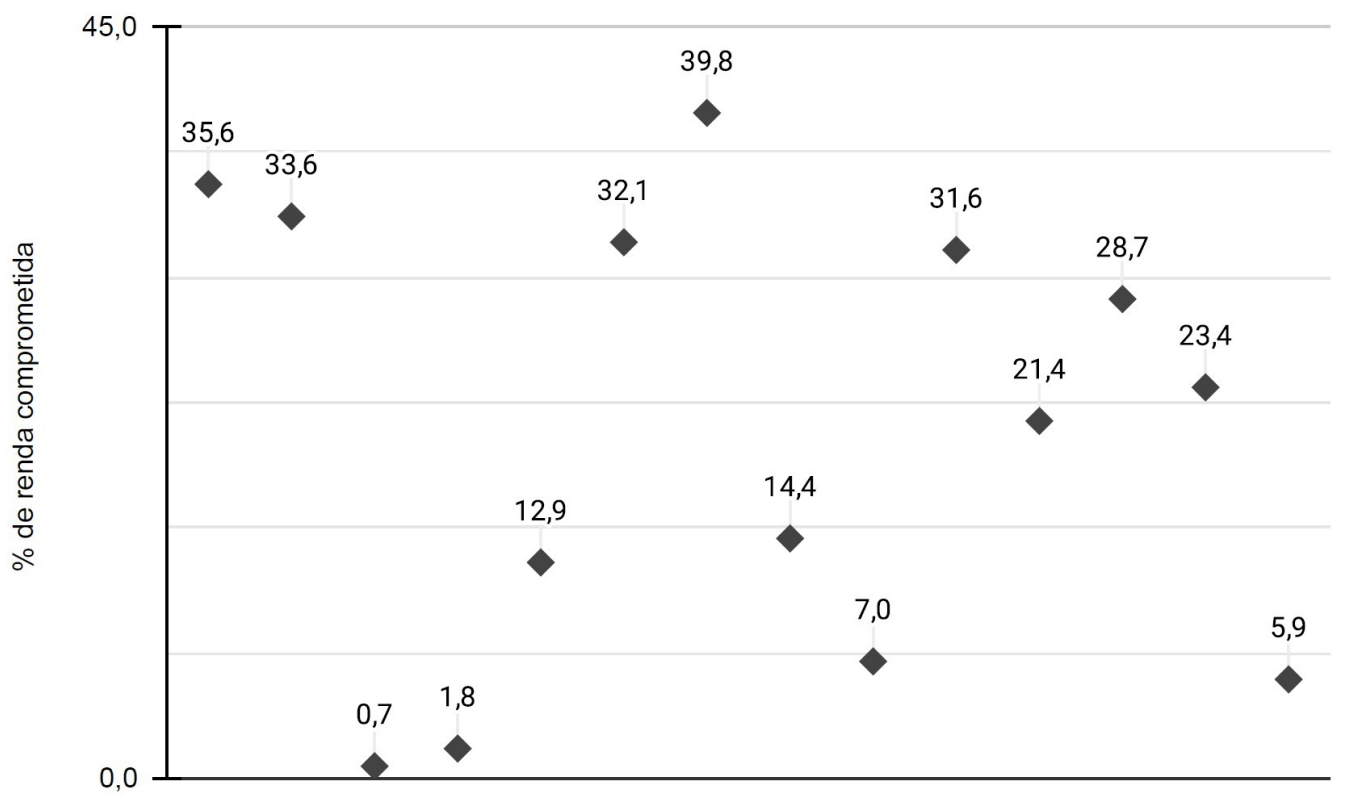

Figura 1. Distribuição do comprometimento da renda salarial dos policiais militares que cometeram suicídio em Santa Catarina, ocorridos entre 2012 e 2016

Tabela 2. Classificação individual do comportamento dos policiais militares da carreira de praças que cometeram suicídio em Santa Catarina no período de 2012 a 2016

\begin{tabular}{lccc}
$\begin{array}{c}\text { Classificação individual } \\
\text { do comportamento }\end{array}$ & Critério & $\mathbf{N}$ & $\%$ \\
\hline Excepcional & $\begin{array}{c}\text { Quando no período de oito (8) anos de efetivo serviço } \\
\text { não tenha sofrido qualquer punição disciplinar }\end{array}$ & 7 & 50 \\
\hline Ótimo & $\begin{array}{c}\text { Quando no período de quatro (4) anos de efetivo } \\
\text { serviço tenha sido punido com até uma detenção }\end{array}$ & 4 & 28,57 \\
\hline Bom & Quando no período de dois (2) anos de efetivo serviço & 1 & 7,14 \\
\hline tenha sido punido com até duas prisões & Quando no período de um (1) ano de efetivo serviço \\
tenha sido punido com até duas prisões & 0 & 0 \\
\hline Mau & $\begin{array}{c}\text { Quando no período de um (1) ano de efetivo serviço } \\
\text { tenha sido punido com mais de duas prisões }\end{array}$ & 0 & 0 \\
\hline
\end{tabular}

que apresentavam alguma punição disciplinar, as mais frequentes se referiam a faltas e atrasos no trabalho, ausência de zelo com materiais da organização ou com o próprio fardamento, além da entrega de documentos fora do prazo exigido pela instituição.

O Regulamento Disciplinar da Polícia Militar do Estado de Santa Catarina estabelece critérios e classifica o comportamento disciplinar dos policiais da carreira de praças em: excelente, ótimo, bom, insuficiente e mau (Tabela 2). Já a carreira dos oficiais não possui classificação para o comportamento disciplinar.

Nenhum dos policiais suicidas possuía problemas de conduta disciplinar. Dos policiais militares da carreira de praças, 6 apresentaram excelente comportamento disciplinar e nenhuma punição em um período de oito anos de efetivo serviço, 4 (28,57\%) estavam classificados no comportamento ótimo, e 1 (7,14\%), no bom.

Não foi possível acessar os dados sobre os dias de afastamento do trabalho dos três policiais militares suicidas que já estavam na condição de "aposentados" por causa das configurações do sistema de recursos humanos utilizado; portanto, não foram analisados. 
Considerando os 11 casos de autoextermínio investigados, a média de dias de afastamento do trabalho por motivo de saúde nos cinco anos anteriores ao suicídio foi de 117 dias, com mínimo de 13 dias e máximo de 438 dias de afastamento.

Não havia a informação do local do suicídio em 6 dos casos analisados. Na amostra restante, o espaço mais comum para o cometimento do suicídio foi a própria residência (42,86\% dos casos), uma morte no próprio local de trabalho (quartel) e uma no interior do próprio veículo. O método mais comum para o suicídio foi a arma de fogo, ocorrido em $5(35,71 \%)$ casos, seguido por enforcamento, com 4 (28,57\%) casos. Faltaram informações quanto ao método utilizado em cinco casos analisados.

Nos documentos examinados, havia poucas informações contextuais sobre as situações vivenciadas pelos policiais militares suicidas na época da autolesão. No entanto, foi possível identificar algumas situações importantes nos documentos disponibilizados pela Diretoria de Saúde e Promoção Social, como o policial estar em processo de separação conjugal ou respondendo processo disciplinar de exclusão da organização, além de situações como tratamentos para depressão e para dependência química e transferências do local de trabalho sem o consentimento e vontade do militar.

\section{DISCUSSÃO}

A taxa de suicídio em homens brasileiros é, em média, quatro vezes maior que a das mulheres ${ }^{19}$ e no estado de Santa Catarina essa taxa passa a ser cinco a seis vezes maior ${ }^{6}$. Assim como nesta investigação, outros estudos evidenciaram maiores índices de suicídio entre policiais do sexo masculino 7,10 .

A mortalidade no sexo masculino por suicídio é maior do que no sexo feminino em todos os países do mundo, exceto na $\mathrm{China}^{20}$. É fator de risco o fato de os homens buscarem ajuda com menor frequência quando comparados às mulheres e de utilizarem de estratégias de enfrentamento desadaptativas como inexpressividade emocional e abuso de substâncias psicoativas mais frequentemente ${ }^{21}$. Além disso, é necessário considerar o predomínio do sexo masculino nas organizações militares ${ }^{22-24}$.

O método escolhido para o suicídio possui relação com o acesso aos meios para o seu cometimento. Casos de suicídios com arma de fogo obtiveram um significativo aumento de $49,8 \%$ entre 1980 e $2012^{19}$. Na força policial francesa, a arma de serviço foi o principal método escolhido para o suicídio ${ }^{10}$.

Para o policial, a arma de fogo é mais do que um instrumento de trabalho, é símbolo de autoridade e poder, tornando-se uma parte da sua identidade ${ }^{25}$. O fácil acesso às armas de fogo e o conhecimento sobre seu manuseio favorecem a elaboração de um plano mais letal para o cometimento do autoextermínio e podem justificar o predomínio desse método encontrado na amostra desta pesquisa.

O resultado encontrado é relevante para a PMSC, a qual regulamenta seu serviço de avaliação psicológica para porte de arma de fogo dos policiais militares por portarias e atos institucionais, cujas situações restritivas para o porte de arma de fogo implicam na suspensão preventiva do porte. Essa suspensão temporária do porte também ocorre sempre que os policiais militares apresentam sinais de adoecimento mental ou afastamento do trabalho por diagnósticos de transtornos mentais e comportamentais. Nessas situações, os policiais militares são realocados para funções administrativas até o recebimento de aptidão para o porte de arma de fogo, decorrido do processo de avaliação psicológica realizado por psicólogo da instituição. Também é oferecido aos policiais militares acompanhamento psicológico gratuito, realizado por policiais militares psicólogos da instituição.

Um programa de apoio aos policiais realizado nas cidades de Montreal e Quebec, no Canadá, reduziu em 78,9\% ( $p<0,008)$ as taxas de suicídio a partir de intervenções complementares entre si: treinamento para todas as unidades policiais sobre a natureza do suicídio; identificação do risco de suicídio e como ajudar um colega em dificuldade; uso de uma linha telefônica exclusiva de apoio aos agentes da polícia, que tratavam de situações traumáticas no trabalho, situações de gênero e homossexualidade, alcoolismo e outras 
dependências, e problemas conjugais e de relacionamento; treinamentos específicos em prevenção de suicídio aos supervisores e representantes sindicais; e campanhas publicitárias de informação sobre a prevenção do suicídio e existência do programa de apoio para todos os membros da força policial.

Foram encontradas relações entre suicídio policial e sentimento de desesperança, apoio institucional e sintomas de transtorno de estresse pós-traumático. Os resultados encontrados indicam que as práticas administrativas e a falta de apoio da instituição possuem efeitos significativamente maiores na percepção de desesperança dos policiais do que o perigo de trabalhar no policiamento de rua ${ }^{11}$. A PMSC tem promovido medidas de caráter continuado enfocadas na prevenção do estresse ocupacional, da síndrome do esgotamento profissional, do transtorno de estresse pós-traumático e do transtorno de ajustamento e utiliza como estratégia o encaminhamento do policial militar ao serviço de psicologia da instituição sempre que participar de ocorrências emocionalmente impactantes.

Outra fonte relevante de apoio ao suicídio é o suporte familiar. Em policiais civis de Santa Catarina a percepção de suporte familiar é um fator de proteção para os policiais afastados do trabalho em razão de sofrimento psíquico ${ }^{26}$. A percepção de suporte familiar colaborou, inclusive, para a recuperação do policial e o retorno à atividade.

A dinâmica familiar, entretanto, também pode ter um papel decisivo no adoecimento dos agentes da lei. Os problemas na vida conjugal são, em $70 \%$ dos casos, a principal causa de suicídio dos policiais franceses ${ }^{10}$. Um estudo epidemiológico do suicídio em Santa Catarina encontrou maior número de suicídios em pessoas casadas do que nas solteiras ${ }^{6}$. Esta investigação encontrou casos de suicídio por situação de separação conjugal, porém são necessários mais estudos para comprovar tal associação na amostra.

A escolaridade pode ser vista como um fator protetivo em relação ao suicídio, funcionando como uma forma de fortalecimento do indivíduo ${ }^{27,28}$. Estudos brasileiros têm mostrado a maior incidência de suicídio em pessoas com até ensino médio ${ }^{29-31}$. A baixa escolaridade pode influenciar o modo como o indivíduo se percebe e suas as relações sociais, implicando baixa autoestima e aumento do risco ao suicídio ${ }^{32}$.

A carreira militar determina as chances de adoecimento. Militares das graduações mais baixas da carreira possuem a função de executores das ações institucionais desenvolvidas pelos gestores, o que torna esse estrato de trabalhadores mais propenso a alguns riscos e perigos da função policial, como o policiamento de rua. O predomínio do suicídio nas graduações mais baixas das carreiras militares também foi encontrado em outras polícias militares brasileiras, como a do Rio de Janeiro' ${ }^{12}$ e a do Rio Grande do Sul' .

Ao se tratar de relações interpessoais, cabe destacar que, entre os militares, elas são pautadas em preceitos rígidos e de alto rigor prescritivo ${ }^{23,33-35}$. No contexto do militarismo, a hierarquia é consubstanciada no acatamento à sequência de autoridade e à disciplina, além da rigorosa observância e acatamento integral das normas, que devem ser mantidas em todas as circunstâncias, tornando a hierarquia e a disciplina dois pilares inseparáveis e interdependentes da vida militar ${ }^{22,36}$. A cobrança da sociedade por uma postura exemplar dos profissionais de segurança pública expõe o policial às pressões internas e externas de tensão, que podem levar ao seu adoecimento físico e psíquico ${ }^{37}$.

É possível que, com o passar dos anos, os policiais militares acumulem sinais de desgaste físico e mental em razão dos anos expostos aos riscos ocupacionais da profissão. A faixa etária com maior quantidade de casos de suicídio na amostra foi entre 40 e 47 anos, indo ao encontro de outros estudos realizados no estado ${ }^{6,38}$.

De maneira geral, os militares estão submetidos a regimes de trabalho e de previdência diferentes da população civil. O predomínio dos suicídios de policiais em final de carreira ou aposentados recentemente pode ter relação com as mudanças drásticas da organização de tempo, de renda e do papel social desempenhado até o momento. A perda da sensação que o trabalho oferece, criando uma ausência do lugar social que o lar não consegue preencher, é um fator relevante associado ao suicídio ${ }^{39}$.

As condições de saúde mental e de suicídio estão ligadas, entre outras situações, aos problemas financeiros e de trabalho ${ }^{40}$. Nesse sentido, as dificuldades financeiras ou 
comprometimento de parte da renda salarial para o pagamento de dívidas ou empréstimos podem ter contribuído para os casos de suicídio estudados nesta investigação. A falta de dinheiro interfere na condição de vida do sujeito e no acesso aos serviços de apoio, além de mantê-lo em frequente estado de preocupação $0^{41,42}$.

Em dados levantados sobre transtornos psiquiátricos, aproximadamente $95 \%$ dos suicidas ou dos que tentaram suicídio apresentavam diagnóstico de transtorno mental ${ }^{6}$. O tempo necessário para resolução de situações que aumentam o risco de suicídio, como depressão, dependência química, problemas financeiros, processos de separação conjugal ou de exclusão da corporação, pode ser superior à média de dias afastados do trabalho dos encontrados na amostra desta investigação. Nesse sentido, ressalta-se a importância de considerar o tempo necessário de recuperação física e mental do militar condicionado à resolução dos problemas que o levaram a adoecer, bem como ampliar a atuação de serviços de saúde da PMSC no auxílio à solução desses problemas.

Por fim, embora este trabalho não tenha examinado as tentativas de suicídio dos policiais militares, elas são um dos principais fatores de risco para uma futura execução do plano inicial. O tratamento de uma pessoa que tentou se suicidar é uma estratégia indispensável para evitar um futuro autoextermínio ${ }^{43}$, pois pessoas com histórico de tentativas recorrentes apresentam maior predisposição ao suicídio completo ${ }^{44}$, devendo essa informação ser considerada como um sinal de alerta pela organização.

Cabe destacar a importância e relevância do tema para o contexto de segurança pública. A falta de informações mais detalhadas sobre os casos de suicídio ocorridos dificultou a compreensão desse fenômeno na PMSC. Contudo, considera-se que os resultados encontrados possibilitam intervenções preventivas com base nas situações-problema identificadas nos casos de suicídio analisados e nas características socio-ocupacionais fornecidas.

Pesquisas futuras podem examinar as condições e circunstâncias que levam ao suicídio dos policiais militares em outras fontes de informação importantes não abordadas neste trabalho, como colegas, comandantes e familiares dos suicidas, além de policiais militares que tentaram suicídio, que podem contribuir de forma significativa.

\section{REFERÊNCIAS}

1. Bastos O. Suicídio e depressão. Revista de Neurologia, Psiquiatria e Neurocirurgia. 2010;58:37-44.

2. Durkheim E. O suicídio - um estudo sociológico. Rio de Janeiro: Zahar; 1897.

3. World Health Organization. Relatório sobre a saúde no mundo: saúde mental - nova concepção, nova esperança. Genebra:WHO; 2001.

4. World Health Organization. Suicide [Internet]. Genebra:WHO; 2017 [citado em 2018 Out 23]. Disponível em: http://www.who.int/mediacentre/factsheets/fs398/en/

5. Word Health Organization. Word suicide report: preventing suicide: a global imperative. Geneva: WHO; 2014.

6. Sehnem SB, Palosqui V. Características epidemiológicas do suicídio no estado de Santa Catarina. Fractal: Revista de Psicologia. 2014;26(2):366-378. http://dx.doi.org/10.1590/1984-0292/624.

7. Gomes DAR, de Araújo RMF, Gomes MS. Incidence of suicide among military police officers in South Brazil - An 11 year retrospective cohort study. Compr Psychiatry. 2018;85:61-6. http://dx.doi.org/10.1016/j. comppsych.2018.06.006. PMid:29981945.

8. Chae MH, Boyle JD. Police suicide: prevalence, risk, and protective factors. Policing. 2013;36(1):91-118 http://dx.doi.org/10.1108/13639511311302498.

9. LeardMann CA, Powell TM, Smith TC, Bell MR, Smith B, Boyko EJ, et al. Risk factors associated with suicide in current and former US military personnel. JAMA. 2013;310(5):496-506. http://dx.doi.org/10.1001/ jama.2013.65164. PMid:23925620.

10. Encrenaz G, Miras A, Contrand B, Séguin M, Moulki M, Queinec R, et al. Suicide dans la Police nationale française: trajectoires de vie et facteurs associés. Encephale. 2016 ago;42(4):304-13. http://dx.doi. org/10.1016/j.encep.2015.08.004. PMid:26452434.

11. Violanti JM, Andrew ME, Mnatsakanova A, Hartley TA, Fekedulegn D, Burchfiel CM. Correlates of hopelessness in the high suicide risk police occupation. Police Pract Res. 2016;17(5):408-19. http://dx.doi. org/10.1080/15614263.2015.1015125. PMid:26752981. 
12. Miranda D. Porque policiais se matam? Diagnóstico e prevenção do comportamento suicida na polícia militar do Estado do Rio de Janeiro. Rio de Janeiro: Mórula Editorial, 2016.

13. Silva R, Matos C, Valdivia B, Cascaes F, Barbosa P. Revisión sistemática acerca de laactividad física y de lasalud de policías. Rev Med (São Paulo). 2013;21(1):75-85.

14. Barros VV, Martins LF, Saitz R, Bastos RR, Ronzani TM. Mental health conditions, individual and job characteristics and sleep disturbances among firefighters. J Health Psychol. 2013;18(3):350-8. http:// dx.doi.org/10.1177/1359105312443402. PMid:22517948.

15. Oliveira KL, Santos LM. Percepção da saúde mental em policiais militares da força tática e de rua. Sociologias. 2010;25(12):224-50. http://dx.doi.org/10.1590/S1517-45222010000300009.

16. Silva MB, Vieira SB. O processo de trabalho do militar estadual e a saúde mental. Saúde e Sociedade. Saude Soc. 2008;17(4):161-70. http://dx.doi.org/10.1590/S0104-12902008000400016.

17. Oliveira MM. Como fazer pesquisa qualitativa. Petrópolis (RJ): Vozes, 2007.

18. Moreira SV. Análise documental como método e como técnica. In Duarte J, Barros A, organizadores. Métodos e técnicas de pesquisa em comunicação. São Paulo: Atlas; 2005.

19. Waiselfisz JJ. Mapa da violência 2014: os jovens do Brasil [Internet]. Brasília: IBICT; 2014 [citado em 2018 Out 23]. Disponível em: http://bibjuventude.ibict.br/jspui/handle/192/80

20. Aucejo AMD, Suay FM, Barricarte JJS. Un estudio de la dinámica del suicidio por sexos y provincias en España. In: XXVI Jornadas de ASEPUMA y XIV Encuentro Internacional Anales de ASEPUMA; 2018; Sevilla. Madrid: ASEPUMA; 2018. p. 1-11.

21. Moller-Leimkuhler AM. The gender gap in suicide and premature death or: why are men so vulnerable? Eur Arch Psychiatry Clin Neurosci. 2003 fev;253(1):1-8. http://dx.doi.org/10.1007/s00406-003-0397-6. PMid:12664306.

22. Minayo MCS, Souza ER, Constantino P. Missão prevenir e proteger: condições de vida, trabalho e saúde dos policiais militares do Rio de Janeiro. Rio de Janeiro: FIOCRUZ; 2008.

23. Souza ER, Minayo MCS, Silva JG, Pires TO. Fatores associados ao sofrimento psíquico de policiais militares da cidade do Rio de Janeiro, Brasil. Cad Saude Publica. 2012;28(7):1297-311. http://dx.doi.org/10.1590/ S0102-311X2012000700008. PMid:22729260.

24. Lima FP, BlankVLG, Menegon FA. Prevalência de transtorno mental e comportamental em Policias Militares/ SC, em licença para tratamento de saúde. Psicologia (Cons Fed Psicol). 2015;35(3):824-40. http://dx.doi. org/10.1590/1982-3703002242013.

25. Santos SF. Suicídio nas forças policiais: um estudo comparativo na PSP, GNR e PJ [dissertação]. Porto: Instituto de Ciências Biomédicas Abel Salazar, Universidade do Porto; 2007.

26. Castro MCA, Cruz RM. Prevalência de transtornos mentais e percepção de suporte familiar em policiais civis. Psicologia (Cons Fed Psicol). 2015;35(2):271-89. http://dx.doi.org/10.1590/1982-370300702013.

27. Seleghim MR, Bellasalma ACM, Mathias TAF, Oliveira MLF. Caracterização das tentativas de suicídio entre idosos. Cogitare Enferm. 2012;17(2):277-83. http://dx.doi.org/10.5380/ce.v17i2.25815.

28. World Health Organization. Word Heath Statistics 2014: a wealth of information on global public health. Genebra:WHO; 2014.

29. Fernandes DAA, Ferreira NS, Castro JGD. Perfil epidemiológico das tentativas de suicídio em PalmasTocantins, de 2010 a 2014. Tempus, Actas de Saúde Colet. 2016;10(4):9-23. http://dx.doi.org/10.18569/ tempus.v11i1.2016.

30. Pedrosa NFNC, Barreira DA, Rocha DQC, Barreira MA. Análise dos principais fatores epidemiológicos relacionados ao suicídio em uma cidade no interior do Ceará, Brasil. J Health \& Biol Sci. 2018;6(4):399-404. http://dx.doi.org/10.12662/2317-3076jhbs.v6i4.2068.p399-404.2018.

31. Faria NMX, Klosinski RFS, Rustick G, Oliveira LDM. Saúde mental dos trabalhadores da saúde pública em Bento Gonçalves, no Rio Grande do Sul. Rev Bras Med Trab. 2018;16(2):145-57. http://dx.doi.org/10.5327/ Z1679443520180196. PMid:32270079.

32. Mann M, Hosman CMH, Schaalma HP, de Vries NK. Self-esteem in a broad spectrum approach for mental health promotion. Health Educ Res. 2004;19(4):357-72. http://dx.doi.org/10.1093/her/cyg041. PMid:15199011.

33. Souza KMOD, Velloso MP, Oliveira SS. A profissão de bombeiro militar e a análise da atividade para compreensão da relação trabalho-saúde: revisão da literatura. In: Anais do VIII Seminário de Saúde do Trabalhador (em continuidade ao VII Seminário de Saúde do Trabalhador de Franca); VI Seminário "O Trabalho em Debate"; 2012; Franca, BR. Franca: UNESP; 2012. 
34. Minayo MCS, Assis SG, Oliveira RVC. Impacto das atividades profissionais na saúde física e mental dos policiais civis e militares do Rio de Janeiro (RJ, Brasil). Cien Saude Colet. 2011;16(4):2199-209. http://dx.doi. org/10.1590/S1413-81232011000400019. PMid:21584461.

35. Menegali TT, Camargo RPM, Rogerio LPW, Carvalho DC, Magajewski FRL. Avaliação da síndrome de Burnout em policiais civis do município de Tubarão (SC). Revista Bras Med Trab. 2010;8(2):78-81.

36. Santa Catarina. Lei no 6.218, de 10 de fevereiro de 1983. Dispõe sobre o Estatuto dos Policiais-Militares do Estado de Santa Catarina, e dá outras providências. Diário Oficial do Estado [Internet], Florianópolis, 1983 [citado em 2018 Out 23]. Disponível em: http://www.pm.sc.gov.br/fmanager/pmsc/upload/dsps/ ART_927398_2014_07_23_083233_I_6218_198.pdf

37. Brito DV, Goulart IB. Avaliação psicológica e prognóstico de comportamento desviante numa corporação militar. Psico-USF. 2005;10(2):149-60. http://dx.doi.org/10.1590/S1413-82712005000200006.

38. Oliveira P, Kock D, Oliveira M, Ramos F, Souza M. Estudo epidemiológico de suicídios no Vale do Itajaí-SC Saber Hum. (online) 2016 ago;6(8):174-90. http://dx.doi.org/10.18815/sh.2016v6n8.145.

39. Faber S. Envelhecimento e elaboração de perdas. A Terceira Idade. 2012;23(53):7-17.

40. Stone DM, Simon TR, Fowler KA, Kegler SR, Yuan K, Holland KM, et al. Vital signs: trends in state suicide rates - United States, 1999-2016 and circumstances contributing to suicide - 27 states, 2015. MMWR Morb Mortal Wkly Rep. 2018;67(22):617-24. http://dx.doi.org/10.15585/mmwr.mm6722a1. PMid:29879094.

41. Moreira RMM, Félix TA, Flôr SMC, Oliveira EN, Albuquerque JHM. Análise epidemiológica dos óbitos por suicídio. SANARE. 2017;16(Supl 1):29-34.

42. Minayo MCS, Cavalcante FG. Suicide in elderly people: a literature review. Rev Saude Publica. 2010 ago;44(4):750-7. http://dx.doi.org/10.1590/S0034-89102010000400020. PMid:20676565.

43. Botega NJ. Comportamento suicida: epidemiologia. Psicol USP [online]. 2014;25(3):231-6. https://doi. org/10.1590/0103-6564D20140004.

44. Vidal CE, Gontijo EC, Lima LB. Tentativas de suicídio: fatores prognósticos e estimativa do excesso de mortalidade. Cad Saude Publica. 2013;29(1):175-87. https://doi.org/10.1590/S0102-311X2013000100020. PMid:23370037. 